Cochrane Database of Systematic Reviews

\title{
Adrenaline (epinephrine) for the treatment of anaphylaxis with and without shock (Review)
}

Sheikh A, Shehata YA, Brown SGA, Simons FER

Sheikh A, Shehata YA, Brown SGA, Simons FER.

Adrenaline (epinephrine) for the treatment of anaphylaxis with and without shock.

Cochrane Database of Systematic Reviews 2008, Issue 4. Art. No.: CD006312.

DOI: 10.1002/14651858.CD006312.pub2.

www.cochranelibrary.com 
TABLE OF CONTENTS

ABSTRACT 1

PLAIN LANGUAGE SUMMARY

BACKGROUND

OBJECTIVES

METHODS

RESULTS

Figure 1.

DISCUSSION

AUTHORS' CONCLUSIONS

ACKNOWLEDGEMENTS

REFERENCES

APPENDICES

WHAT'S NEW

HISTORY

CONTRIBUTIONS OF AUTHORS

DECLARATIONS OF INTEREST

SOURCES OF SUPPORT

INDEX TERMS 
[Intervention Review]

\title{
Adrenaline (epinephrine) for the treatment of anaphylaxis with and without shock
}

\author{
Aziz Sheikh ${ }^{1}$, Yasser A Shehata 2 , Simon GA Brown ${ }^{3}$, F Estelle R Simons 4 \\ 1Asthma UK Centre for Applied Research, Usher Institute of Population Health Sciences and Informatics, The University of Edinburgh, \\ Edinburgh, UK. ${ }^{2}$ Division of Community Health Sciences: GP section, The University of Edinburgh, Edinburgh, UK. ${ }^{3}$ Department of \\ Emergency Medicine, The University of Western Australia at Fremantle Hospital, Fremantle, Australia. ${ }^{4}$ Department of Pediatrics \& Child \\ Health; Department of Immunology, Faculty of Medicine, University of Manitoba, Winnipeg, Canada
}

Contact: Aziz Sheikh, Asthma UK Centre for Applied Research, Usher Institute of Population Health Sciences and Informatics, The University of Edinburgh, Teviot Place, Edinburgh, EH8 9AG, UK. Aziz.Sheikh@ed.ac.uk, asheikh2@partners.org.

Editorial group: Cochrane Emergency and Critical Care Group.

Publication status and date: Stable (no update expected for reasons given in 'What's new'), published in Issue 12, 2018.

Citation: Sheikh A, Shehata YA, Brown SGA, Simons FER. Adrenaline (epinephrine) for the treatment of anaphylaxis with and without shock. Cochrane Database of Systematic Reviews 2008, Issue 4. Art. No.: CD006312. DOI: 10.1002/14651858.CD006312.pub2.

Copyright $(2018$ The Cochrane Collaboration. Published by John Wiley \& Sons, Ltd.

\begin{abstract}
A B S T R A C T
Background

Anaphylaxis is a serious hypersensitivity reaction that is rapid in onset and may cause death. Adrenaline is recommended as the initial treatment of choice for anaphylaxis.

\section{Objectives}

To assess the benefits and harms of adrenaline (epinephrine) in the treatment of anaphylaxis.

\section{Search methods}

In the previous version of our review, we searched the databases until March 2007. In this version we searched the Cochrane Central Register of Controlled Trials (CENTRAL) (The Cochrane Library 2010, Issue 11), MEDLINE (1966 to November 2010), EMBASE (1966 to November 2010), CINAHL (1982 to November 2010), BIOSIS (to November 2010), ISI Web of Knowledge (to November 2010 and LILACS (1982 to November 2010). We also searched websites listing ongoing trials and contacted pharmaceutical companies and international experts in anaphylaxis in an attempt to locate unpublished material.
\end{abstract}

\section{Selection criteria}

We included randomized and quasi-randomized controlled trials comparing adrenaline with no intervention, placebo or other adrenergic agonists were eligible for inclusion.

\section{Data collection and analysis}

Two authors independently assessed articles for inclusion.

\section{Main results}

We found no studies that satisfied the inclusion criteria.

\section{Authors' conclusions}

Based on this review, we are unable to make any new recommendations on the use of adrenaline for the treatment of anaphylaxis. Although there is a need for randomized, double-blind, placebo-controlled clinical trials of high methodological quality in order to define 
the true extent of benefits from the administration of adrenaline in anaphylaxis, such trials are unlikely to be performed in individuals with anaphylaxis. Indeed, they might be unethical because prompt treatment with adrenaline is deemed to be critically important for survival in anaphylaxis. Also, such studies would be difficult to conduct because anaphylactic episodes usually occur without warning, often in a non-medical setting, and differ in severity both among individuals and from one episode to another in the same individual. Consequently, obtaining baseline measurements and frequent timed measurements might be difficult, or impossible, to obtain. In the absence of appropriate trials, we recommend, albeit on the basis of less than optimal evidence, that adrenaline administration by intramuscular (i.m.) injection should still be regarded as first-line treatment for the management of anaphylaxis.

\section{PLAIN LANGUAGE SUMMARY}

\section{Adrenaline for the emergency treatment of anaphylaxis}

Anaphylaxis is a serious allergic reaction that is rapid in onset and may cause death. It is commonly triggered by a food, insect sting, medication, or natural rubber latex. The reaction occurs without warning and can be a frightening experience for those at risk and for their families and friends. Adrenaline (epinephrine) is widely advocated as the main treatment in those individuals experiencing anaphylaxis. There is no other medication with a similar effect on the many body systems that are potentially involved in anaphylaxis. The evidence base in support of the use of adrenaline is unclear. We therefore conducted a systematic review of the literature searching key databases for high quality published and unpublished material on the use of adrenaline for emergency treatment; in addition, we contacted experts in this area and the relevant pharmaceutical companies. Our searches retrieved no randomized controlled trials on this subject. We concluded that the use of adrenaline in anaphylaxis is based on tradition and on evidence from fatality series in which most individuals dying from anaphylaxis had not received prompt adrenaline treatment. Adrenaline appears to be life saving when injected promptly, however, there is no evidence from randomized controlled trials for or against the use of adrenaline in the emergency treatment of anaphylaxis. Given the infrequency of anaphylaxis, its unpredictability and the speed of onset of reactions, conducting such trials is fraught with ethical and methodological difficulties. 


\section{B A C K G R O U N D}

Anaphylaxis is a serious allergic reaction that is rapid in onset and may cause death (Sampson 2006). Trigger factors include foods, insect venoms, medications, anaesthetics, natural rubber latex, and exercise (Brown 2001; Brown 2004a; Kemp 2002; Lieberman 2003; Sampson 2005; Simons 2002a; Simons 2007a; Simons 2007b). Most anaphylactic episodes involve an immediate hypersensitivity reaction following allergen interaction with cellbound immunoglobulin E (IgE). Less commonly other immunologic mechanisms, for example autoimmune mechanisms, are involved; or no immune mechanism is involved, for example when anaphylaxis is triggered by exposure to cold air or water. Some individuals have idiopathic anaphylaxis with no obvious trigger. Regardless of the inciting mechanism, the final common pathway involves release of histamine and other mediators from mast cells and basophils. Distinction between anaphylactic reactions and an anaphylactoid reaction is no longer recommended as the clinical picture and emergency treatment of anaphylaxis are similar regardless of the pathophysiologic mechanism (Johansson 2001; Johansson 2004; Sampson 2006; Simons 2007a).

Anaphylaxis is not a reportable disease and the true incidence is unknown (Bohlke 2004; Hebling 2004; Klein 1995; Lieberman 2006; Neugut 2001; Peng 2004; Sheikh 2001). An estimate of the incidence in the general population is influenced by definitions, which differ from one investigator to another, as well as by coding issues and misclassification errors (Clark 2006). A population-based study using data collected in the mid-1980s calculated an annual incidence of 30 per 100,000 person years, which raised concern that anaphylaxis was frequently not recognized (Yocum 1999). Other studies suggest the true incidence may be up to 590 per 100,000 person years. Anaphylaxis from the four most common triggers (foods, insect stings, medications, and natural rubber latex) may affect more than $1 \%$ of the general population (Neugut 2001) with considerable variations in age (Simons 2002a) and in age-specific aetiology (Alves 2001).

Skin symptoms and signs, including generalised urticaria, flushing, itching, and angioedema (swelling of the subcutaneous tissues), are the most common manifestations of anaphylaxis (in $90 \%$ of those affected) followed by respiratory (70\%) and gastrointestinal (40\%) symptoms; hypotension occurs in $10 \%$ to $30 \%$ (Brown 2001; Brown 2004b; Kemp 2002; Lieberman 2003; Simons 2002b). Symptoms often occur within five to 30 minutes of exposure to the trigger factor, although occasionally they do not develop for several hours. Anaphylaxis may be fatal within minutes, usually through cardiovascular or respiratory compromise, or both (Bock 2007; Greenberger 2007; Pumphrey 2000; Pumphrey 2007). Upper and lower respiratory tract obstruction is commonly reported in fatal cases (Bock 2007; Greenberger 2007; Pumphrey 2007). True mortality rates are unknown in anaphylaxis because of underrecognition and under-diagnosis of the disease (Pumphrey 2000).

The diagnosis of anaphylaxis is based largely on history and physical findings. Laboratory tests have proven to be disappointing in clinical practice. Plasma histamine may be elevated, but it is only reliable when measured within one hour of onset and the levels are not stable during routine handling, so it is seldom used (Lin 2000). Serum or plasma tryptase levels greater than $15 \mathrm{ng} / \mathrm{mL}$ within 12 hours (preferably within three hours) of the onset of an episode is more widely used as a confirmatory test, but this test is usually negative in food-induced anaphylaxis. Serial total serum or plasma tryptase measurements may be more helpful than single measurements (Brown 2004a). Positive skin tests to allergens and elevated allergen-specific IgE levels in serum are not diagnostic of anaphylaxis. Rather, such tests confirm sensitization and provide clinically relevant information that directs risk reduction and the prevention of future episodes by avoidance of specific allergen or allergens; or long-term immunomodulation where relevant, for example with venom immunotherapy for insect sting anaphylaxis (Simons 2007a).

Adrenaline (epinephrine) is widely advocated as the initial treatment of choice for anaphylaxis (Alrasbi 2007; McLeanTooke 2003; Simons 2004). This initial emergency management is supervised by a physician or other healthcare professional when anaphylaxis occurs in a healthcare setting. In this setting intramuscular (i.m.) or intravenous (i.v.) infusion, or both, routes for adrenaline are preferred (Brown 2006). When anaphylaxis occurs in the community, in a non-medical setting, the standard of first-aid treatment is the administration of self-injectable adrenaline into the anterolateral thigh using an EpiPen, Anapen, AnaHelp, Fastject, Twinject, or other adrenaline formulation (Sicherer 2005; Simons 2004).

Adrenaline is an alpha- and beta-adrenergic agonist (that is it acts on two different important classes of receptors in the body) with bidirectional cyclic adenosine monophosphatemediated pharmacologic effects on target organs and a narrow therapeutic index (Simons 2006). It results in vasoconstriction, increased peripheral vascular resistance, decreased mucosal oedema, inotropic and chronotropic effects (increased force and rate of cardiac action), bronchodilation, and decreased mediator release from mast cells and basophils. The plasma and tissue concentrations of adrenaline needed for recovery from anaphylaxis have not yet been defined in humans (Simons 2004). There have been no prospective human studies performed during the management of anaphylaxis to evaluate the bioavailability and optimal dose of adrenaline given intramuscularly or to assess the incidence of adverse effects (Simons 2008). Case reports and large mortality reviews indicate that side effects involving the myocardium can be serious, usually in the setting of inappropriate dosing (an overdose, an inadequately diluted intravenous dose, or an overly rapid rate of infusion) by medical staff (Pumphrey 2000). However, there is now increased awareness that the heart itself may be a target organ in anaphylaxis and that electrocardiographic changes suggesting ischaemia, myocardial failure, and dysrhythmias can occur even if adrenaline has not been given (Brown 2005; Kounis 2006; Marone 2004).

Only the intravenous route was used in the two studies in humans that indicate a beneficial treatment effect for reactions characterised by cardiovascular collapse (Brown 2004b; Fisher 1978). In a canine model of fully-developed anaphylactic shock (defined as hypotension with the blood pressure contained at 50\% of baseline blood pressure), adrenaline $0.01 \mathrm{mg} / \mathrm{kg}$ injected by the intramuscular route was ineffective; an intravenous bolus of $0.01 \mathrm{mg} / \mathrm{kg}$ resulted in transient improvement; and intravenous infusion at 0.19 to $0.45 \mu \mathrm{g} / \mathrm{kg} / \mathrm{min}$ was the only method to produce a sustained improvement (Bautista 2002; Mink 2004). The therapeutic effect in this model was from positive inotropy, with no increases in either systemic vascular resistance or pulmonary arterial wedge pressure. Thus, if a severe reaction develops 
and adrenaline is administered at the generally recommended initial doses for anaphylaxis, which are lower than the doses recommended for resuscitation, it might not adequately counteract the effects of vasodilation and distributive-hypovolaemic shock on its own, even when given as an intravenous infusion (Brown 2005).

In summary, the use of adrenaline in anaphylaxis appears to be based largely on extrapolation from first principles, expert opinion, and tradition.

\section{O B JECT IVES}

To assess the benefits and harms of adrenaline in the treatment of anaphylaxis.

\section{METHODS}

\section{Criteria for considering studies for this review}

\section{Types of studies}

We planned to include randomized controlled trials comparing adrenaline with no intervention, placebo, or other adrenergic agonists. We also planned to include randomized controlled trials comparing different approaches to the administration of adrenaline and quasi-randomized controlled trials, that is trials where an attempt to approximate randomization was made (for example by alternate allocation). Controlled trials with little attempt to minimize bias during allocation were, however, not eligible for inclusion.

\section{Types of participants}

We were interested in all patients (infants, children and adults; community or hospital based) experiencing anaphylaxis caused by food, insect venom, medication, vaccination, latex, or any other trigger.

\section{Types of interventions}

We were interested in studies involving any systemic (intravenous infusion or bolus injection, intramuscular, subcutaneous, or inhaled from a metered-dose inhaler or a nebulizer) administration of adrenaline by the individual, a lay caregiver (of a child), or a medical professional. Adrenaline could have been administered anywhere in the community, including in a physician's office or an ambulance; or anywhere in the hospital, including emergency departments, hospital clinics, dialysis units, wards, operating rooms, and delivery rooms. It may also have been administered after another medication. The comparative treatments of interest were no intervention, placebo, other adrenergic agonists; and different treatment approaches to the administration of adrenaline.

\section{Types of outcome measures}

Our outcome measures of interest were the following.

\section{Primary outcomes}

Death

\section{Secondary outcomes}

1. Resolution of upper airway obstruction

2. Resolution of lower airway obstruction (symptomatic bronchospasm)
3. Improvement in arterial blood pressure (greater than $50 \mathrm{~mm} \mathrm{Hg}$ systolic)

4. Resolution of urticaria

5. Requirement for second dose of adrenaline

6. Admission to hospital

7. Length of emergency department stay

8. Length of hospital stay

9. Re-presentation for therapy within 24 hours

10.Adverse events due to therapy, in either treatment arm

\section{Search methods for identification of studies}

\section{Electronic searches}

In the previous version of our review, we searched all the databases until March 2007.

In this updated version we searched the Cochrane Central Register of Controlled Trials (CENTRAL) (The Cochrane Library 2010, Issue 11) (see Appendix 1); MEDLINE (1966 to November 2010, Appendix 2); EMBASE (1966 to November 2010, Appendix 3); CINAHL (1982 to November 2010, Appendix 4); BIOSIS (1969 to November 2010, Appendix 5); ISI Web of Science (1956 to November 2010, Appendix 6 ); and LILACS (1982 to November 2010), Appendix 7).

We searched MEDLINE using Ovid with the Cochrane randomized controlled trial filter (Higgins 2009) and the following key words: anaphyl $^{*}$ and adrenaline. We adopted our search terms for other databases. We did not apply any language restriction.

\section{Searching other resources}

In an attempt to uncover any additional relevant published data, grey literature, unpublished data, and research in progress, we:

- contacted international experts in anaphylaxis (see Appendix 8);

- contacted relevant pharmaceutical companies (see Appendix 8);

- searched the UK's National Research Register: https:// portal.nihr.ac.uk/Pages/NRRArchive.aspx

- searched websites listing ongoing trials: http:// clinicaltrials.gov/, http://www.controlledtrials.com/ and http:// www.actr.org.au/.

\section{Data collection and analysis}

\section{Selection of studies}

Two authors (YS and AS) independently reviewed titles and abstracts identified from literature searches for relevant trials and selected possibly relevant studies. We reviewed these studies using the full text and assessed them using the inclusion criteria detailed above.

We had agreed that we would resolve any disagreements by discussion between both of the authors; in the case of consensus not being reached, a third author (ES) would become involved and, if necessary, arbitrate.

\section{Data extraction}

We stipulated that two authors (YS and AS) would independently extract data using a suitably adapted version of the data extraction form developed by the Cochrane Anaesthesia Review Group. We stated that we would resolve any disagreements by discussion 
between both of the authors; in the case of consensus not being reached, a third author (ES) was to be involved and, if necessary, arbitrate. This did not prove necessary.

\section{Assessment of methodological quality of included studies}

In our previous version we planned to grade each parameter of trial quality as: A - low risk of bias; B - moderate risk of bias; C - high risk of bias. We planned to make an overall assessment for each randomized controlled trial, using the same rating scale.

In this updated version of the review we planned to assess the quality of included RCTs following the Cochrane approach using the methods detailed in Chapter Eight of the Cochrane Handbook for Systematic Reviews of Interventions (Higgins 2009).

We planned to construct risk of bias tables to support judgements of quality using the Cochrane Risk of Bias tool (Higgins 2009):

- Was the allocation sequence adequately generated?

- Was allocation adequately concealed?

- Was knowledge of the allocated interventions adequately prevented during the study?

- Were incomplete outcome data adequately addressed?

- Are reports of the study free of suggestion of selective outcome reporting?

- Was the study apparently free of other problems that could put it at a risk of bias?

W e planned to record the judgement as 'yes' indicating that the study met that quality parameter, 'no' it did not or 'unclear' indicating that there was insufficient evidence to make a judgement either way.

We planned to display the results by creating a 'Risk of bias' graph and a 'Risk of bias' summary figure using RevMan 5.0 software

We also planned to subject quasi-randomized studies to methodological assessment, in which case two authors (YS and AS) would independently assess study quality; review authors would not be masked to study details. We planned to assess the agreement of review authors on methodological quality assessment and to resolve disagreements by discussion and, if necessary, with the involvement of a third author (ES).

\section{Data analysis}

We proposed to use Review Manager (RevMan 5.0) for data analysis and quantitative data synthesis. For dichotomous data, we planned to calculate individual and pooled statistics as relative risks (RR) with 95\% confidence intervals $(95 \% \mathrm{CI})$. For continuous data, we planned to calculate individual and pooled statistics as mean differences (MD) or standardized means differences, or both, with $95 \% \mathrm{Cl}$. We planned to consider the appropriateness of meta-analysis in the presence of significant clinical or statistical heterogeneity. We assumed significant heterogeneity if the 12 statistic was greater than $40 \%$ (that is more than $40 \%$ of the variability in outcome between trials could not be explained by sampling variation) (Higgins 2002). We planned to undertake metaanalysis using a fixed-effect model in the absence of statistical heterogeneity and a random-effects model if such heterogeneity was likely. We planned to explore any statistical or clinical heterogeneity by using sensitivity or subgroup analysis (see below). We planned to undertake quantitative analyses of outcomes on an intention-to-treat basis, wherever possible. We planned to assess any evidence of publication bias graphically using funnel plots and statistically using Begg and Egger tests (Begg 1994; Egger 1997).

\section{Subgroup analysis}

In the event of uncovering significant heterogeneity, we planned to investigate the heterogeneity by undertaking subgroup analyses. Our subgroups of interest were:

- presence or absence of shock;

- mild or more severe anaphylaxis (Brown 2004b);

- mode of administration of treatment (i.m. versus i.v.; administered by patient versus healthcare professional);

- time from onset of anaphylaxis to receiving treatment;

- age (infants, children, and adults);

- trigger agents (iatrogenic versus community, antibiotic versus other drugs, and muscle relaxants versus other agents).

\section{Sensitivity analysis}

We planned to undertake sensitivity analysis for the allocation of missing data by best and worst case analysis and also to undertake sensitivity analysis on the basis of only including randomized studies. This would allow an assessment of the impact on the review conclusions of excluding quasi-randomized studies, judged to be at increased risk of bias.

\section{RE S U L T S}

\section{Description of studies}

In the previous version of our review, we searched the databases until March 2007 and yielded 382 citations. In this updated version we searched from March 2007 up to November 2010 and found an additional 1036 citations. In total our combined searches found 1418 citations (see Figure 1). 
Figure 1. Search flow diagram

\section{Database Search}

EMBASE:

MEDLINE:

Lilacs:

CENTRAL:

CINAHL:

BIOSIS:

Web of Science:
433

290

16

34

144

174

327

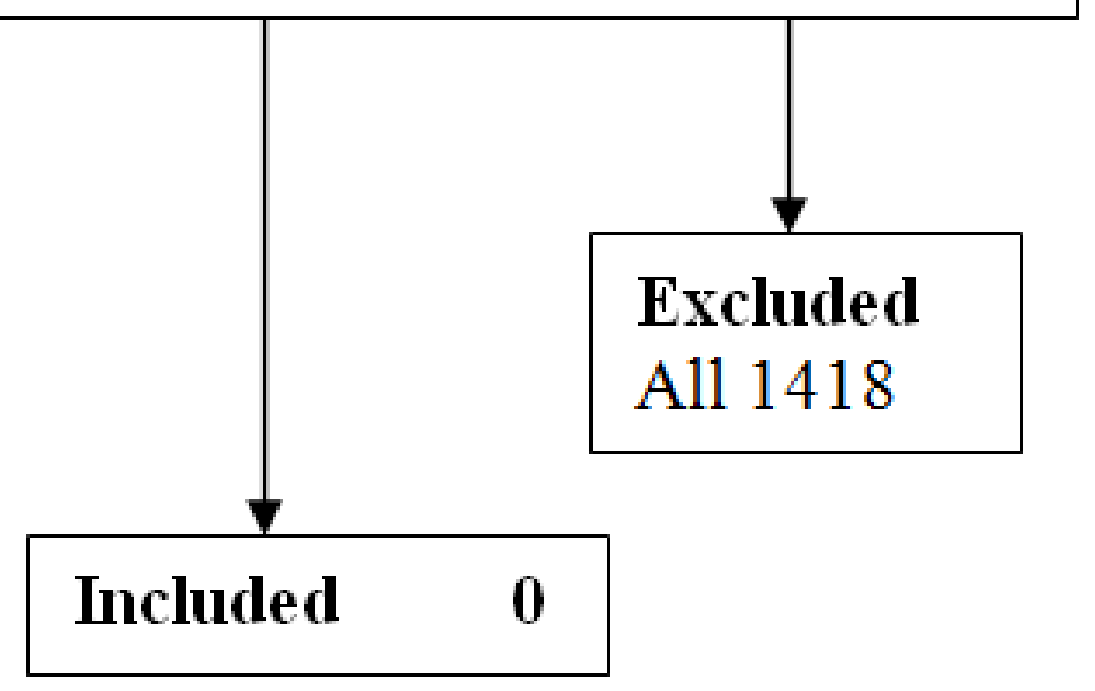

After scrutiny of the abstracts of these studies, no studies fulfilled the inclusion criteria. We contacted context editors and pharmaceutical companies but this failed to contribute any relevant published or unpublished studies. The search of the UK National Research Register, Current Controlled Trials, and Clinical Trials using anaphylaxis as a keyword identified no useful articles.

\section{Risk of bias in included studies}

There were no eligible studies.

\section{Effects of interventions}

There were no eligible studies.

\section{DISCUSSION}

This review failed to uncover any evidence from prospective, randomized or quasi-randomized trials on the effectiveness of adrenaline for the emergency management of anaphylaxis. Given the relative infrequency of the condition, the speed of onset, the often unexpected occurrence, and the established place of adrenaline in treatment guidelines internationally (Alrasbi 2007) this lack of evidence for a treatment that was introduced well before the evidence-based medicine era is perhaps unsurprising (Simons 2007b).

The optimal route of administration and the optimal dose of adrenaline have not yet been defined. In children, it has been shown that subcutaneous administration of adrenaline was associated with a striking difference in the time of 
maximum plasma adrenaline concentrations compared with the intramuscular route (Simons 1998). Other studies showed that the average maximum plasma concentration was also significantly higher for the intramuscular route than for the subcutaneous route of administration (Simons 2001). Moreover, guidelines regarding the treatment of anaphylaxis have recommended against use of the subcutaneous route (Chamberlain 1999).

Some disagreement exists about the recommended dose of adrenaline. Almost all of the literature agrees on $0.01 \mathrm{mg} / \mathrm{kg}$ in infants and children. Although North American, Australasian, and current UK guidelines suggest a maximum initial dose of 0.3 to 0.5 $\mathrm{mg}$ of adrenaline in adults, some older European literature suggests 0.5 to $1.0 \mathrm{mg}$ as a maximum initial intramuscular dose in adults (Alrasbi 2007; Soar 2008).

Delayed injection of adrenaline in anaphylaxis is reported to be associated with mortality (Bock 2001; Bock 2007; Pumphrey 2000; Pumphrey 2007; Greenberger 2007). Given that current evidence supports the relative safety of intramuscular adrenaline, and early administration is believed to be associated with an improved survival, any patient with a serious allergic reaction that is rapid in onset should be a candidate for adrenaline by auto-injector.

Adrenaline has been associated with the induction of fatal cardiac arrhythmias and myocardial infarction. Major adverse events usually occur when adrenaline has been given in an excessive dose, an inadequately diluted intravenous dose, or an overly rapid rate of infusion (Brown 1998; Fischer 1995; Montanaro 2002; Pumphrey 2000). Historically, those individuals thought to be particularly at risk of adverse effects of adrenaline include elderly patients and patients with hypertension, arteriopathies, or known ischaemic heart disease ( Bock 2001; Bock 2007; Greenberger 2007; Muller 2007; Pumphrey 2000; Pumphrey 2007; Sampson 1992); however, these patients may also be at increased risk from the anaphylactic episode itself. It is difficult, particularly in retrospect, to dissect potential adverse effects of adrenaline from the known effects of anaphylaxis (Brown 1998; Marone 2004; Pumphrey 2000). Because of potential harm from the use of intravenous adrenaline in inexperienced hands, guidelines generally recommend that the intravenous route is reserved for cases that do not respond to initial treatment with intramuscular adrenaline and where cardiovascular collapse and cardiac arrest is considered imminent. A controlled infusion is safer than bolus administration (Soar 2008). It should be given in a resuscitation area that has electrocardiography and physiological monitoring by medical and nursing staff who are trained in its use (Johnston 2003).

In the past, adrenaline has been available worldwide in metereddose inhaler formulations. These are no longer available in many countries due to their chlorofluorocarbon (CFC) propellant content and the phase out of CFC-containing medications. Inhalation of a few puffs of adrenaline from a pressurized metered-dose inhaler is not adequate for treatment of most of the symptoms in anaphylaxis. In order to achieve systemic effects, adults need to inhale 20 to 30 puffs, and children need to inhale 10 to 20 puffs (Heilborn 1986; Simons 2000). For an overview of the context in which adrenaline should be used in anaphylaxis: provide supplemental oxygen; place patient in the supine position, if tolerated; start volume resuscitation; and prepare for intubation, the appropriate references should be consulted (Soar 2008).
As there are no controlled trials there is no way to estimate the risk in relation to benefit. Based on the current evidence, we believe that the benefit of using appropriate doses of intramuscular adrenaline is likely to far exceed the risk. Anaesthetists, who see anaphylaxis relatively commonly, usually have sophisticated monitoring in place before, during, and after the event; they report a rapid and predictable response to adrenaline that is near universal. It should be stressed that adrenaline is not contraindicated in individuals with underlying ischaemic heart disease as the decrease in filling pressure due to anaphylaxis is likely to result in further coronary ischaemia (Montanaro 2002). Careful monitoring and avoidance of an adrenaline overdose is necessary in these patients, however.

There is a strong clinical impression that prompt injection of adrenaline is life saving in anaphylaxis. Given the uncertainties surrounding its use, however, a firmer evidence base needs to be developed, if possible. Conducting research in this area is challenging for several reasons, including:

- the established position of adrenaline treatment thereby making it difficult to argue for placebo-controlled trials;

- the ethical issues involved in obtaining informed consent (or deferring consent) in emergency situations (Dec Helsinki 1996);

- difficulty in conducting double-blind, placebo-controlled studies due to the transient pharmacologic effects (pallor, tachycardia, tremor) of adrenaline in standard doses that reverse airway obstruction and circulatory collapse;

- logistical issues: anaphylactic episodes usually occur without warning, often in a non-medical setting; differ in severity from one individual to another, and from one episode to another in the same individual;

- difficulty in obtaining baseline measurements;

- the lack of any information on the pharmacokinetics and pharmacodynamics of adrenaline when given to humans during anaphylaxis and a lack of any prospectively collected information on clinical outcomes, both of which are required to construct valid hypotheses and inform sample size calculations for a clinical trial.

\section{AUTHORS' CONCLUSIONS}

\section{Implications for practice}

We found no relevant evidence for adrenaline use in the treatment of anaphylaxis. We are, therefore, unable to make any new recommendations based on the findings of this review. Guidelines on the management of anaphylaxis need to be more explicit about the basis of their recommendations regarding the use of adrenaline.

\section{Implications for research}

Given the routine use of adrenaline in the management of anaphylaxis, there is a need for academic debate about the ethics and practicality of mounting randomized trials in order to define the true extent, if any, of benefits from the administration of adrenaline in anaphylaxis. Specifically, more information is required on the subset of patients more likely to benefit from this therapy and the most appropriate preparations, route, and dose of administration. 
Although placebo-controlled trials of adrenaline in anaphylaxis would be unethical, it might be possible to conduct randomized controlled trials comparing two different doses of adrenaline, or two different routes of administration of adrenaline, in addition to other standard-of-care treatments (Simons 2008).

Any future trials would need to consider in particular:

- appropriate sample size with power to detect expected difference;

- careful definition and selection of target patients;

- appropriate comparator therapy;

- appropriate outcome measures;

- careful elucidation of any adverse effects; and

- the cost-effectiveness of the therapy.

\section{ACK N O WLEDGEMENTS}

November 2010: We would like to thank the Anaesthesia Group's Trials Search Co-ordinator (Karen Hovhannisyan) for rerunning all the searches for the updated version of the review.

We would like to thank Prof Anthony Brown and Prof Hugh Sampson for their help and advice during the preparation of this review. Our thanks to Anna Wierzoch and Jane Cracknell for their help during the course of conducting this review.

As part of the pre-publication editorial process, this review has been commented on by an editor and three peer reviewers (who are external to the editorial team), one or more members of the Cochrane Consumer Network's international panel of consumers and the Anaesthesia Group's Trials Search Co-ordinator.

We would thank to thank Prof Mike Bennett, Dr Jose $M^{a}$ Negro, Dr Ulrich Müller and Dr Phil Lieberman, Rosemary Humphreys and Janet Wale for their help and editorial advice during the preparation of this review. 


\section{R E F E R E N C E S}

\section{Additional references}

\section{Alrasbi 2007}

Alrasbi M, Sheikh A. Comparison of international guidelines for the emergency medical management of anaphylaxis. Allergy 2007;62:838-41.

\section{Alves 2001}

Alves B, Sheikh A. Age specific aetiology of anaphylaxis. Archives of Disease in Childhood 2001;85:348.

\section{Bautista 2002}

Bautista E, Simons FER, Simons KJ, Becker AB, Duke K, Tillett M, et al. Epinephrine fails to hasten hemodynamic recovery in fully developed canine anaphylactic shock. International Archives of Allergy and Applied Immunology 2002;128:151-64.

\section{Begg 1994}

Begg CB, Mazumdar M. Operating characteristics of a rank correlation test for publication bias. Biometrics 1994;50:1088-101.

\section{Bock 2001}

Bock SA, Munoz-Furlong A, Sampson HA. Fatalities due to anaphylactic reactions to foods. The Journal of Allergy and Clinical Immunology 2001;107:191-3.

\section{Bock 2007}

Bock SA, Munoz-Furlong A, Sampson HA. Further fatalities caused by anaphylactic reactions to food, 2001-2006. The Journal of Allergy and Clinical Immunology 2007;119:1016-8.

\section{Bohlke 2004}

Bohlke K, Davis RL, DeStefano F, Marcy SM, Braun MM, Thompson RS, Vaccine Safety Datalink Team. Epidemiology of anaphylaxis among children and adolescents enrolled in a health maintenance organization. The Journal of Allergy and Clinical Immunology 2004;113:536-42.

\section{Brown 1998}

Brown AFT. Therapeutic controversies in the management of acute anaphylaxis. Journal of Accident \& Emergency Medicine 1998;15:89-95.

\section{Brown 2001}

Brown AF, McKinnon D, Chu K. Emergency department anaphylaxis: a review of 142 patients in a single year. The Journal of Allergy and Clinical Immunology 2001;108:861-6.

\section{Brown 2004a}

Brown SG, Blackman KE, Stenlake V, Heddle RJ. Insect sting anaphylaxis; prospective evaluation of treatment with intravenous adrenaline and volume resuscitation. Emergency Medicine Journal 2004;21:149-54.

\section{Brown 2004b}

Brown SG. Clinical features and grading of anaphylaxis. The Journal of Allergy and Clinical Immunology 2004;114:371-6.

\section{Brown 2005}

Brown SGA. Cardiovascular aspects of anaphylaxis: implications for treatment and diagnosis. Current Opinion in Allergy and Clinical Immunology 2005;5:359-64.

Brown 2006

Brown SG. Anaphylaxis: clinical concepts and research priorities. Emergency Medicine Australasia 2006;18:155-69.

\section{Chamberlain 1999}

Chamberlain D. Emergency medical treatment of anaphylactic reactions. Project team of the resuscitation council (UK). Journal of Accident \& Emergency Medicine 1999;16:243-7.

\section{Clark 2006}

Clark S, Gaeta TJ, Kamarthi GS, Camargo CA. ICD-9-CM coding of emergency department visits for food and insect sting allergy. Annals of Epidemiology 2006;16:696-700.

\section{Dec Helsinki 1996}

World Health Organization. Declaration of Helsinki. BMJ 1996;313:1448-9.

\section{Egger 1997}

Egger M, Davey Smith G, Schneider M, Minder C. Bias in meta- analysis detected by a simple, graphical test. $B M J$ 1997;315:629-34.

\section{Fischer 1995}

Fischer M. Fortnightly review: treatment of acute anaphylaxis. BMJ 1995;311:731-3.

\section{Fisher 1978}

Fisher MM. Acute life-threatening reactions to contrast media. Aust Radiol 1978;22:365-71.

\section{Greenberger 2007}

Greenberger PA, Rotskoff BD, Lifschultz B. Fatal anaphylaxis: postmortem findings and associated comorbid diseases. Annals of Allergy, Asthma \& Immunology 2007;98:252-7.

\section{Hebling 2004}

Helbling A, Hurni T, Mueller UR, Pichler WJ. Incidence of anaphylaxis with circulatory symptoms: a study over a 3-year period comprising 940,000 inhabitants of the Swiss Canton Bern. Clinical and Experimental Allergy 2004;34:285-90.

\section{Heilborn 1986}

Heilborn H, Hjemdahl P, Daleskog M, Adamsson U. Comparison of subcutaneous injection and high-dose inhalation of epinephrine ? implications for self-treatment to prevent anaphylaxis. Journal of Allergy and Clinical Immunology 1986;76:1174-9.

\section{Higgins 2002}

Higgins JP, Thompson SG. Quantifying heterogeneity in a metaanalysis. Statistics in Medicine 2002;21:1539-58. 


\section{Higgins 2009}

Higgins JPT, Green S (editors). Cochrane Handbook for Systematic Reviews of Interventions Version 5.0.2 [updated September 2009]. The Cochrane Collaboration, 2008. Available from www.cochrane-handbook.org.

\section{Johansson 2001}

Johansson SG, Hourihane JO, Bousquet J, BruijnzeelKoomen C, Dreborg S, Haahtela T, et al. A revised nomenclature for allergy. An EAACI position statement from the EAACI nomenclature task force. Allergy 2001;56:813-24.

\section{Johansson 2004}

Johansson SGO, Bieber T, Dahl R, Friedmann PS, Lanier BQ, Lockey RF, et al. Revised nomenclature for allergy for global use: Report of the Nomenclature Review Committee of the World Allergy Organization, October 2003. The Journal of Allergy and Clinical Immunology 2004;113:832-6.

\section{Johnston 2003}

Johnston SL, Unsworth J, Gompels M. Adrenaline given outside the context of life threatening allergic reactions. $B M J$ 2003;326:589-90.

\section{Kemp 2002}

Kemp SF, Lockey RF. Anaphylaxis: a review of causes and mechanisms. The Journal of Allergy and Clinical Immunology 2002;110:341-8.

\section{Klein 1995}

Klein JS, Yocum MW. Underreporting of anaphylaxis in a community emergency room. The Journal of Allergy and Clinical Immunology 1995;95:637-8.

\section{Kounis 2006}

Kounis NG. Kounis syndrome (allergic angina and allergic myocardial infarction): a natural paradigm?. International Journal of Cardiology 2006;110:7-14.

\section{Lieberman 2003}

Lieberman PL. Anaphylaxis and anaphylactoid reactions. Middleton's Allergy: Principles and Practice, 6th edition. Mosby, 2003.

\section{Lieberman 2006}

Lieberman P, Camargo C, Bohlke K, Jick H, Miller R, Sheikh A, et al. Epidemiology of anaphylaxis: findings of the ACAAI Epidemiology of Anaphylaxis Working Group. Annals of Allergy, Asthma \& Immunology 2006;97:596-602.

\section{Lin 2000}

Lin RY, Schwartz LB, Curry A, Pesola GR, Knight RJ, Lee HS, et al. Histamine and tryptase levels in patients with acute allergic reactions: An emergency department-based study. The Journal of Allergy and Clinical Immunology 2000;106:65-71.

\section{Marone 2004}

Marone G, Bova M, Detoraki A, Onorati AM, Rossi FW, Spadaro G. The human heart as a shock organ in anaphylaxis. Novartis Foundation Symposium 2004;257:133-49.

\section{McLean-Tooke 2003}

McLean-Tooke AP, Bethune CA, Fay AC, Spickett GP. Adrenaline in the treatment of anaphylaxis: what is the evidence?. BMJ 2003;327:1332-5.

\section{Mink 2004}

Mink SN, Simons FER, Simons KJ, Becker AB, Duke K. Constant infusion of epinephrine, but not bolus treatment, improves haemodynamic recovery in anaphylactic shock in dogs. Clinical and Experimental Allergy: Journal of the British Society for Allergy and Clinical Immunology 2004;34:1776-83.

\section{Montanaro 2002}

Montanaro A, Bardana EJ Jr. The mechanisms, causes and treatment of anaphylaxis. Journal of Investigational Allergology \& Clinical Immunology 2002;1:2-11.

\section{Muller 2007}

Muller U. Cardiovascular disease and anaphylaxis. Current Opinion in Allergy and Clinical Immunology 2007;7:337-41.

\section{Neugut 2001}

Neugut Al, Ghatak AT, Miller RL. Anaphylaxis in the United States: an investigation into its epidemiology. Archives of Internal Medicine 2001;161:15-21.

\section{Peng 2004}

Peng MM, Jick H. A population-based study of the incidence, cause, and severity of anaphylaxis in the United Kingdom. Archives of Internal Medicine 2004;164:317-9.

\section{Pumphrey 2000}

Pumphrey RS. Lessons for management of anaphylaxis from a study of fatal reactions. Clinical and Experimental Allergy: Journal of the British Society for Allergy and Clinical Immunology 2000;30:1144-50.

\section{Pumphrey 2007}

Pumphrey RSH, Gowland MH. Further fatal allergic reactions to food in the United Kingdom, 1999-2006. The Journal of Allergy and Clinical Immunology 2007;119:1018-9.

\section{RevMan 5.0 [Computer program]}

The Nordic Cochrane Centre, The Cochrane Collaboration. Review Manager (RevMan). Version 5.0. Copenhagen: The Nordic Cochrane Centre, The Cochrane Collaboration, 2008.

\section{Sampson 1992}

Sampson HA, Mendelson L, Rosen JP. Fatal and near-fatal anaphylactic reactions to food in children and adolescents. The New England Journal of Medicine 1992;327:380-4.

\section{Sampson 2005}

Sampson HA, Munoz-Furlong A, Bock SA, Schmitt C, Bass R, Chowdhury BA, et al. Symposium on the definition and management of anaphylaxis: summary report. The Journal of Allergy and Clinical Immunology 2005;115:584-91.

\section{Sampson 2006}

Sampson HA, Munoz-Furlong A, Campbell RL, Adkinson NF Jr, Bock SA, Branum A, et al. Second symposium on the definition 
and management of anaphylaxis: summary report. Second National Institute of Allergy and Infectious Disease/Food Allergy and Anaphylaxis Network symposium. The Journal of Allergy and Clinical Immunology 2006;117:391-7.

\section{Sheikh 2001}

Sheikh A, Alves B. Age, sex, geographical and socio-economic variations in admissions for anaphylaxis: analysis of four years of English hospital data. Clinical and Experimental Allergy: Journal of the British Society for Allergy and Clinical Immunology 2001;31:1571-6.

\section{Sicherer 2005}

Sicherer SH, Simons FER. Quandaries in prescribing an emergency action plan and self-injectable epinephrine for firstaid management of anaphylaxis in the community. The Journal of Allergy and Clinical Immunology 2005;115:575-83.

\section{Simons 1998}

Simons FER. Epinephrine absorption in children with a history of anaphylaxis. Journal of Clinical Immunology 1998;101:33-7.

\section{Simons 2000}

Simons FER, Gu X, Johnston L, Simons KJ. Can epinephrine inhalations be substituted for epinephrine injection in children at risk for systemic anaphylaxis?. Pediatrics 2000;106:1040-4.

\section{Simons 2001}

Simons FER, Gu X, Simons KJ. Epinephrine absorption in adults: intramuscular versus subcutaneous injection. The Journal of Allergy and Clinical Immunology 2001;108:871-3.

\section{Simons 2002a}

Simons FER, Peterson S, Black CD. Epinephrine dispensing patterns for an out-of-hospital population: a novel approach to studying the epidemiology of anaphylaxis. The Journal of Allergy and Clinical Immunology 2002;110:647-51.

\section{Simons 2002b}

Simons FER, Chad ZH, Gold M. Real-time reporting of anaphylaxis in infants, children and adolescents by physicians involved in the Canadian Pediatric Surveillance Program. The Journal of Allergy and Clinical Immunology 2002;109 Suppl:181.

\section{Simons 2004}

Simons FER. First-aid treatment of anaphylaxis to food: Focus on epinephrine. The Journal of Allergy and Clinical Immunology 2004;113:837-44.

\section{Simons 2006}

Simons FER. Anaphylaxis, killer allergy: Long-term management in the community. The Journal of Allergy and Clinical Immunology 2006;117:367-77.

\section{Simons 2007a}

Simons FER, Frew AJ, Ansotegui IJ, Bochner BS, Finkelman F, Golden DBK, et al. Risk assessment in anaphylaxis: current and future approaches. The Journal of Allergy and Clinical Immunology 2007;120 Suppl:2-24.

\section{Simons 2007b}

Simons FE, Sheikh A. Evidence-based management of anaphylaxis. Allergy 2007;62:827-9.

\section{Simons 2008}

Simons FER. Emergency treatment of anaphylaxis: Revised UK guidelines are a concise evidence based resource. British Medical Journal 2008;336:1141-2.

\section{Soar 2008}

Soar J, Pumphrey R, Cant A, et al. for the Working Group of the Resuscitation Council (UK). Emergency treatment of anaphylactic reactions: Guidelines for healthcare providers. Resuscitation 2008;77:157-69.

\section{Yocum 1999}

Yocum MW, Butterfield JH, Klein JS, Volcheck GW, Schroeder DR, Silverstein MD. Epidemiology of anaphylaxis in Olmsted County: A population-based study. The Journal of Allergy and Clinical Immunology 1999;104:452-6.

\section{APPENDICES}

\section{Appendix 1. Search strategy for CENTRAL, The Cochrane Library}

\#1 MeSH descriptor Anaphylaxis explode all trees \#2 anaphylact* near (react ${ }^{\star}$ or shock* or syndrom $^{\star}$ ) $\# 3$ acute near (allergic react ${ }^{\star}$ )

$\# 4$ anaphylaxis

\#5 (\#1 OR \#2 OR \#3 OR \#4)

\#6 MeSH descriptor Sympathomimetics explode all trees

\#7 MeSH descriptor Catecholamines explode all trees

\#8 MeSH descriptor Epinephrine explode all trees \#9 MeSH descriptor Norepinephrine explode all trees \#10 sympathomimetic* or Catecholamin* or Adrenalin* or Epinephrin* or Noradrenalin* or EpiPen or Anapen* \#11 (\#6 OR \#7 OR \#8 OR \#9 OR \#10)

\#12 (\#5 AND \#11)

\section{Appendix 2. Search strategy for MEDLINE (Ovid SP)}

1. exp Anaphylaxis/ or (anaphyla* adj3 (react* or shock* or syndrome* or systemic or idiopathic)).mp. or (acute adj3 allergic react*).mp. 
2. exp sympathomimetics/ or Catecholamines/ or Adrenaline/ or Epinephrine/ or Noradrenaline/ or (epipen or anapen or catecholamine* or epinephrin* or noradrenalin* or adrenalin*).mp.

3. 1 and 2

4. ((randomized controlled trial or controlled clinical trial).pt. or randomized.ab. or placebo.ab. or drug therapy.fs. or randomly.ab. or trial.ab. or groups.ab.) not (animals not (humans and animals)).sh.

5. 3 and 4

\section{Appendix 3. Search strategy for EMBASE (Ovid SP)}

1. exp anaphylaxis/ or exp anaphylactic shock/ or (anaphyla* adj3 (react* or shock ${ }^{\star}$ or syndrome* or systemic or idiopathic)).mp. or (acute adj3 allergic react*).mp.

2. exp adrenergic receptor stimulating agent/ or exp catecholamine/ or exp catecholamine/ or noradrenalin/ or (epipen or anapen or catecholamine ${ }^{\star}$ or epinephrin* or noradrenalin* or adrenalin*).mp.

3. 1 and 2

4. (randomized-controlled-trial/ or randomization/ or controlled-study/or multicenter-study/ or phase-3-clinical-trial/or phase-4-clinicaltrial/ or double-blind-procedure/ or single-blind-procedure/ or (random* or cross?over ${ }^{\star}$ or factorial* or placebo* or volunteer* or ((singl ${ }^{\star}$ or doubl* or trebl* or tripl*) adj3 (blind* or mask $\left.{ }^{\star}\right)$ )).ti,ab.) not (animals not (humans and animals)).sh.

5. 3 and 4

\section{Appendix 4. Search strategy for CINAHL (EBSCO host)}

S1 (MM "Anaphylaxis")

S2 TX anaphylax* or anaphilact*

S3 S1 or S2

S4 (MH "Sympathomimetics+")

S5 (MH "Catecholamines+")

S6 (MH "Epinephrine")

S7 TX sympathomimetic* or Catecholamin* or Adrenalin* or Epinephrin* or Noradrenalin* or EpiPen or Anapen*

$\mathrm{S} 8 \mathrm{~S} 4$ or $\mathrm{S} 5$ or $\mathrm{S} 6$ or $\mathrm{S} 7$

S9 S3 and S8

\section{Appendix 5. Search strategy for BIOSIS Previews (Ovid SP)}

1 (anaphylact* or anaphylax* or (acute adj3 allergic)).mp.

2 (epipen or anapen or catecholamine* or epinephrin* or noradrenalin* or adrenalin*).mp.

31 and 2

\section{Appendix 6. Search strategy for ISI Web of Science}

(TS=anaphylax* OR TS=anaphylact*) AND (TS=Sympathomimetic* OR TS=Catecholamin* OR TS=Adrenalin* OR TS=Epinephrin* OR TS=Noradrenalin ${ }^{\star}$ OR TS=EpiPen OR TS=Anapen)

\section{Appendix 7. Search strategy for LILACS (BIREME)}

("epipen" or "anapen" or "catecholamine" or "epinephrine" or "noradrenaline" or "adrenaline") and ("ANAPHYLAXIA" or "ANAPHYLAXIS" or "ANAPHYLAXIS/" or "ANAPHYLACTIC REACTION" or "ANAPHYLACTIC REACTION/" or "anaphylax\$" or "anaphylact\$")

\section{Appendix 8. List of experts and pharmaceutical companies contacted}

\section{Contact names}

Prof. H.A. Sampson

Prof. A.F. Brown

Prof. J.M. Negro-Alvarez

Prof. A.D. Moneret - Vautrin

Prof. U Muller 
(Continued)

Prof. M Fisher

\section{Prof. J Ring}

Dr. L.P. Lieberman

\section{Dr. P.W. Ewan}

Dr. R.S. Pumphrey

Dr. A. Helbling

Dr. R Lin

Dr. S Clark

Dr. D Golden

Dr. R Lockey

Dr. A Bock

Dr. S Kemp

Dr. C Camargo

ALK-Abelló (UK) Ltd

Abbott Laboratories Ltd

\section{UCB Pharma Ltd}

Meridian Medical Technology Inc

Cell Therapeutics (UK) Ltd

CSL Biotherapies

Lincoln Medical Ltd

Dey Laboratories

International Medication Systems (UK) Ltd

WHAT'S NEW

\begin{tabular}{lll}
\hline Date & Event & Description \\
\hline 14 December 2018 & Amended & Editorial team changed to Cochrane Emergency and Critical Care \\
\hline 18 June 2014 & Review declared as stable & $\begin{array}{l}\text { This Cochrane review has been marked as stable no longer being } \\
\text { updated as there are no randomized controlled trials (RCTs) and }\end{array}$
\end{tabular}




\begin{tabular}{lll}
\hline Date & Description \\
\hline & $\begin{array}{l}\text { for ethical reasons there are unlikely to be any RCTs in the future. } \\
\text { If the situation changes then the authors will update the review. }\end{array}$ \\
\end{tabular}

\section{HISTORY}

Protocol first published: Issue 1, 2007

Review first published: Issue 4, 2008

\begin{tabular}{lll}
\hline Date & Event & Description \\
\hline 29 January 2016 & Amended & New contact details for lead author \\
\hline 23 February 2012 & Amended & Contact details updated. \\
\hline 18 January 2012 & Amended & Contact details updated. \\
\hline 15 December 2010 & Amended & $\begin{array}{l}\text { New declaration of interest statement. Previously all authors } \\
\text { stated: 'none known'. }\end{array}$ \\
\hline 30 November 2010 & New search has been performed & $\begin{array}{l}\text { In the previous version of our review, we searched the databases } \\
\text { until March 2007. In this updated version we reran the database } \\
\text { searches until November 2010. } \\
\text { We did not find any new studies which fitted our inclusion crite- } \\
\text { ria. } \\
\text { We updated the methods section. }\end{array}$ \\
\hline 11 December 2007 & Amended & Aziz Sheikh's affiliation updated; typos corrected. \\
\hline
\end{tabular}

\section{CONTRIBUTIONS OFAUTHORS}

Conceiving the review: Aziz Sheikh (AS) and F. Estelle R Simons (ES)

Co-ordinating the review: AS

Undertaking manual searches: Yasser A Shehata (YS)

Screening search results: YS and AS

Organizing retrieval of papers: YS

Screening retrieved papers against inclusion criteria: YS and AS

Appraising quality of papers: Not applicable

Abstracting data from papers: Not applicable

Writing to authors of papers for additional information: YS and AS

Providing additional data about papers: Not applicable

Obtaining and screening data on unpublished studies: Not applicable

Data management for the review: YS

Entering data into Review Manager (RevMan 5.0): YS

RevMan statistical data: Not applicable

Other statistical analysis not using RevMan: Not applicable

Double entry of data: (data entered by person one: data entered by person two:) Not applicable

Interpretation of data: Not applicable

Statistical analysis: Not applicable

Writing the review: AS, ES, Simon GA Brown (SB) and YS

Securing funding for the review: AS 
Performing previous work that was the foundation of the present study: AS, ES and SB Guarantor for the review (one author): AS

Person responsible for reading and checking review before submission: AS

\section{DECLARATIONS OF INTEREST}

Aziz Sheikh:has obtained funding from ALK-Abello to support conference attendance by members of our research group.

Yasser A Shehata, Simon GA Brown and F Estelle R Simons: none known.

\section{SOURCES OF SUPPORT}

\section{Internal sources}

- University of Edinburgh, UK.

\section{External sources}

- No sources of support supplied

\section{INDEX TERMS}

\section{Medical Subject Headings (MeSH)}

Adrenergic Agonists [*therapeutic use]; Anaphylaxis [complications] [*drug therapy]; Epinephrine [ ${ }^{\star}$ therapeutic use]; Shock [complications] [ ${ }^{*}$ drug therapy]; Vasoconstrictor Agents [therapeutic use]

\section{MeSH check words}

Humans 